\title{
ERRATUM
}

\section{Parental mosaicism of JAG1 mutations in families with Alagille syndrome}

Joannis Giannakudis, Albrecht Röpke, Annegret Kujat, Malgorzata Krajewska-Walasek, Helen Hughes, Jean-Pierre Fryns, Agnes Bankier, David Amor, Mike Schlicker and Ingo Hansmann

European Journal of Human Genetics (2001) 9, 209-216

Figure 6 in the above paper was printed with an incorrect legend. The figure and legend are reproduced correctly below.

A)

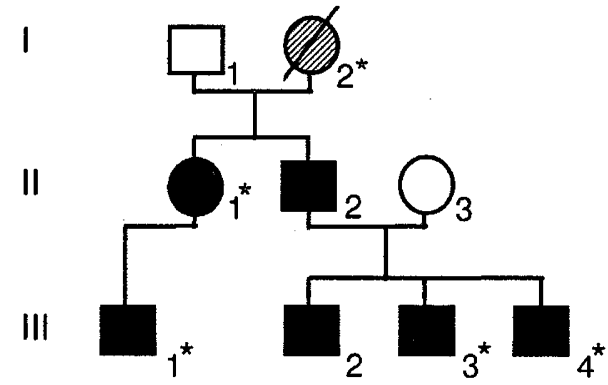

B)

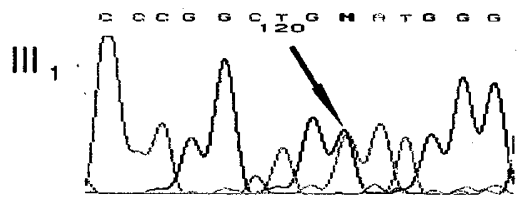

$\mathrm{I}_{2}$
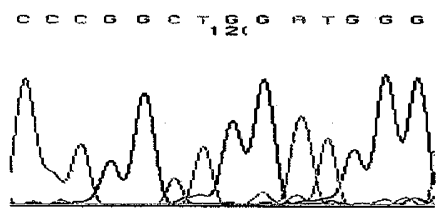

\begin{tabular}{|c|c|c|c|c|}
\hline Face & Liver & Heart & Eye & Skeleton \\
\hline - & - & - & - & - \\
\hline $\begin{array}{l}+ \\
\text { no de }\end{array}$ & ta & - & NR & NR \\
\hline+ & + & + & NR & $N R$ \\
\hline+ & + & + & + & $N R$ \\
\hline+ & + & + & + & $\mathrm{NR}$ \\
\hline
\end{tabular}

Figure 6 Case 5 (W442X). (A) Three generation pedigree with AGS and symptoms of the affected individuals. Hatched symbol: presumed mosaicism due to facial appearance; NR: not reported. Asterisks indicate individuals who were included in the mutation

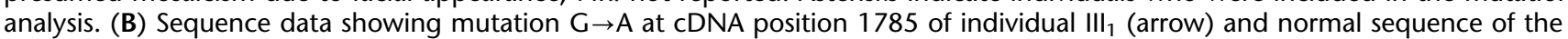
grandmother. 